\title{
EFEKTIVITAS COGNITIVE BEHAVIOR THERAPY UNTUK MENURUNKAN BODY SHAME
}

\author{
Riananda Regita Cahyani' \\ Fathul Lubabin Nuqul ${ }^{2}$ \\ Fakultas Psikologi \\ Universitas Islam Negeri Maulana Malik Ibrahim Malang
}

\begin{abstract}
Individuals who are unable to comply with the standards of ideal physical conditions found in the community are vulnerable to criticism or scorn. Criticism of the individual's physical appearance performed by other people and themselves tend to make individuals experience feelings of shame about their bodies. One of the factors that influence body shame is the thoughts individuals have about their physical condition. This study aims to determine the effectiveness of cognitive behavioral therapy to reduce the level of body shame. This research method uses quasi-experiments. The research subjects were 17 people. The experimental group was given Cognitive behavior therapy while the control group was given makeup skills training or Beauty Class. Data analysis used by using One-way ANOVA. The results showed that effective Cognitive Behavior Therapy to reduce the body shame level of research subjects compared to Beauty Class
\end{abstract}

Keywords: Body Shame, Cognitive Behavior Therapy, Quasi Experiment

\begin{abstract}
ABSTRAK. Individu yang tidak mampu sesuai dengan standar kondisi fisik ideal yang terdapat di masyarakat rentan mendapatkan kritikan maupun cibiran. Kritikan terhadap penampilan fisik individu yang dilakukan orang lain maupun diri sendiri cenderung membuat individu mengalami perasaan malu terhadap tubuhnya. Salah satu faktor yang mempengaruhi body shame adalah pemikiran yang dimiliki individu terhadap kondisi fisiknya. Penelitian ini bertujuan untuk mengetahui efektivitas cognitive behavior therapy untuk menurunkan tingkat body shame. Metode penelitian ini menggunakan kuasi eksperimen. Subyek penelitian berjumlah 17 orang. Kelompok eksperimen diberi perlakuan cognitive behavior therapy sedangkan kelompok kontrol diberikan pelatikan ketrampilan bermake-up atau beauty class. Analisis data menggunakan Oneway ANOVA. Hasil penelitian menunjukkan bahwa cognitive behavior therapy efektif untuk menurunkan tingkat body shame subyek penelitian dibandingkan dengan beauty class
\end{abstract}

Kata kunci : Body Shame, Cognitive Behavior Therapy, Quasi Experiment

\footnotetext{
${ }^{1}$ Korespondensi artikel ini dapat melalui: rirecha.01@gmail.com atau

2 Lubabin_nuqul@uin-malang.ac.id
} 
Pandangan negatif yang dimiliki individu terhadap kondisi fisik diri sendiri dan orang lain, mendorong individu untuk melakukan perubahan penampilannya. Kekhawatiran diri dapat memotivasi perilaku sosial seseorang karena kecenderungan untuk memberikan kesan positif agar mampu menyesuaikan diri dengan lingkungan sosial (Myers, 2012). Internalisasi lingkungan, tekanan interpersonal, berat badan, pilihan pribadi, serta jenis kelamin merupakan faktor yang mempengaruhi body shame (Dinartika, Wisnuwardhani, \& Arbiyah, 2014). Individu cenderung memiliki keinginan untuk diterima oleh lingkungan sosialnya, salah satunya dengan melakukan perubahan pada kondisi fisiknya. Di sisi lain perubahan yang dilakukan terkadang dapat membuat seseorang menderita dan tertekan.

Perubahan penampilan yang dilakukan perempuan agar sesuai dengan standar kecantikan mampu menimbulkan dampak negatif pada dirinya. Contoh kasus mengenai gangguan makan yang disebabkan oleh keinginan untuk memiliki tubuh kurus, misalnya. Pemikiran masyarakat mengenai standar tubuh ideal adalah perempuan yang bertubuh kurus. Perempuan menjadi khawatir akan pandangan negatif orang lain mengenai tubuhnya yang gemuk (Davidson, Neale, \& Kring, 2014). Selain itu cara untuk cantik dengan instan juga mengakibatkan dampak negatif seperti melakukan suntik vitamin $\mathrm{C}$ agar memiliki kulit putih secara cepat. Namun terdapat dampak yang ditimbulkan jika tubuh terlalu banyak menerima asupan vitamin $\mathrm{C}$ yaitu sakit kepala, sakit perut, insomnia, dan batu ginjal (Putri, 2018).

Hal terpenting, sebenarnya, untuk mengatasi body shame adalah pemikiran dan tindakan diri sendiri. Ada dua faktor internal yang dapat dilakukan seseorang untuk mengatasi dampak negatif dari body shaming yaitu body surveillance serta kontrol terhadap penampilan diri (Daye, Webb, \& Jafari, 2014). Memandang diri secara positif, menghindari membandingkan penampilan dengan orang lain, menjaga penampilan diri dengan percaya diri dan menunjukkan penampilan yang sesuai dengan dirinya. Hal tersebut dinilai mampu untuk mengatasi dampak negatif body shaming.

Penilaian seseorang terhadap situasi dan cara menginterpretasikan kejadian akan memberikan pengaruh terhadap kondisi reaksi emosional yang akan mempengaruhi tindakan yang dilakukan (Putranto, 2016). Penilaian negatif individu mengenai dirinya akan mengakibatkan seseorang melakukan tindakan yang disesuaikan dengan reaksi emosional. Hal ini juga berlaku ketika individu memandang dirinya kurang cantik, menimbulkan reaksi malu dan tidak percaya diri, dan pada beberapa individu mereka memutuskan untuk melakukan perubahan pada dirinya namun juga terdapat individu yang memilih memendam perasaan tersebut. Muncul juga personalisasi pada diri individu, yaitu pemikiran menyalahkan diri sendiri walaupun kesalahan tersebut timbul dari orang lain. Selain itu juga, individu yang mengalami body shame melakukan kesalahan dalam memberi label pada dirinya. Individu yang tidak sesuai dengan standar kecantikan seringkali menganggapan bahwa dirinya tidak berharga.

Mengubah pemikiran seseorang dapat dilakukan dengan menerapkan Cognitive Behavior Therapy (CBT). Cognitive Behavior Therapy (CBT) merupakan bentuk pendekatan yang menggunakan teknik kognitif dan perilaku individu untuk membantu individu melakukan modifikasi terhadap suasana hati dan perilaku dengan melakukan perubahan melalui pikiran (Palmer, 2011). Terapi ini menekankan perubahan pada distorsi kognitif sehingga mampu mengubah tingkah laku yang 
disebabkan distorsi kognitif. Perlunya mengubah keyakinan yang dimiliki seseorang agar mampu mengubah tindakannya.

Fokus penggunaan Cognitive Behavior Therapy (CBT) untuk mengatasi pikiran negatif pada orang yang mengalami body shaming. Pikiran negatif dapat membuat seseorang mengurung diri dari orang lain dan mengkritik diri sendiri. Ketika memiliki pikiran negatif terhadap diri sendiri maka perasaan yang dimiliki cenderung negatif dan berdampak juga pada kesehatan tubuh. Pikiran negatif yang dimiliki dapat diatasi menggunakan Cognitive Behavior Therapy (CBT) dengan menunjukkan cara untuk mengembangkan kemampuan melihat peristiwa dari berbagai sudut pandang serta mempertanyakan anggapan yang dimiliki dan menemukan kesalahan pemikiran yang dialami (Wilding \& Milne, 2013).

Cognitive Behavior Therapy (CBT) bukan satu-satunya terapi yang memiliki orientasi kognitif dan tingkah laku. Terapi Rasional Emotif (TRE) yang dikembangkan Ellis juga memiliki orientasi kognitif dan tingkah laku. Maksud dari orientasi kognitif dan tingkah laku adalah cara berpikir seseorang mempengaruhi bagaiman orang tersebut bertindak. Walaupun begitu, terdapat perbedaan konsep antara Cognitive Behavior Therapy (CBT) dan Terapi Rasional Emotif (TRE). Pada Cognitive Behavior Therapy (CBT) masalah yang terjadi karena adanya disfungsi keyakinan yang tidak sesuai dengan proses kognitif secara umum, sedangkan pada Terapi Rasional Emotif (TRE) menekankan pada inti dari pikiran yang irasional dan melibatkan emotive (Putranto, 2016).

Body shame dipengaruhi pola pikir individu, karena adanya evaluasi negatif terhadap dirinya. Berdasarkan pandangan non kognitif, berpikir bahwa orang merasa malu dan rendah diri karena emosi. Namun dari sudut pandang kognitif, cara pikir seseorang menentukan perilaku dirinya. Salah satu cara untuk menghindari dampak negatif dari body shame adalah membangun pertahanan dari dalam. Cognitive Behavior Therapy (CBT) dinilai mampu untuk diterapkan berulang-ulang oleh klien tanpa bantuan dari terapis, sehingga hal ini efektif untuk mengubah pemikiran yang terdistori mengenai dirinya. Penggunaan Cognitive Behavior Therapy (CBT) dapat mengurangi tingkat body shame seseorang. Individu yang mengalami body shame memiliki pemikiran negatif terhadap dirinya yang disebabkan adanya tindakan membandingkan penampilan dengan orang lain atau mengkritik penampilan sendiri.

\section{METODE PENELITIAN Desain Eksperimen}

Penelitian ini menggunaka desain quasi eksperimen. Desain memiliki kriteria pengelompokan subyek dilakukan melalui teknik non-random. Persiapan yang dilakukan dalam pemberian intervensi yakni melakukan uji coba instrumen terhadap 50 mahasiswi. Mencari pemateri untuk memberikan intervensi dengan kriteria yang dijelaskan pada bagian pemateri. Menyusun modul intervensi (Modul Cognitive Behavior Therapy dan Modul Beauty Class). Perlakuan yang diberikan pada kelompok eksperimen berupa Cognitive Behavior Therapy (CBT) yang terdiri dari lima sesi berdurasi 60 menit per sesi. Sesi pertama mengenai asesmen dan diagnosa awal, sesi kedua yaitu mencari emosi negatif, pikiran otomatis, dan keyakinan utama, sesi ketiga mengenai menyusun intervensi dengan memberikan konsekuensi positif dan negatif, sesi keempat yaitu mengenai formulasi status, fokus terapi, intervensi tingkah laku, dan sesi terakhir berfokus pada pencegahan kekambuhan. Perlakuan yang diberikan pada kelompok kontrol berupa Beauty Class. Beauty Class terdiri dari dua sesi. Sesi yang pertama yaitu perkenalan dan edukasi skincare yang berdurasi 90 menit. Sesi kedua 
berisi mengenai edukasi alat dan produk make up dan post-test berdurasi 90 menit.

\section{Subyek Penelitian}

Kriteria subyek penelitian yaitu pernah mengalami body shaming, berjenis kelamin perempuan, mahasiswa semester 7 , dan berusia 20-22. Individu yang bersedia mengikuti seleksi berjumlah 60 orang. Seleksi kelompok eksperimen 39 orang sedangkan kelompok kontrol 21 orang. Setelah itu, peneliti menanyakan kesediaan individu yang mengikuti setiap sesi pelatihan. Pada kelompok eksperimen dan kelompok kontrol, diambil menjadi 15 orang.

Subyek penelitian berjumlah 30 orang yang dibagi pada 2 kelompok yang masingmasing kelompok beranggotakan 15 orang. Subyek dipilih berdasarkan kesediaan mengikuti pelatihan yang berjumlah 2 sesi ataupun 5 sesi sehingga pembagian subjek dalam kelompok eksperimen dan kontrol dengan nonrandom assigment. Subyek dianalisis secara individual dan kelompok untuk mengetahui penurunan body shame pada masing-masing subyek serta mengetahui pengaruh pemberian perlakuan pada kelompok eksperimen dan kelompok kontrol.

Subjek penelitian kelompok eksperimen, semula berjumlah 15 orang. Namun pada sesi pertama dan kedua, subyek yang hadir berjumlah 11 orang. Sedangkan pada sesi ketiga dan keempat, subyek yang hadir berjumlah 9 orang. Pada sesi kelima, subyek penelitian yang hadir berjumlah 8 orang. Sehingga hanya terdapat 8 orang subyek yang hadir dalam setiap sesi pelatihan sehingga terdapat 8 subyek yang mengerjakan lembar prates dan pascates. Namun salah satu subyek dari 8 orang tersebut dinyatakan gugur karena kurang mampu mengikuti instruksi dengan baik dan masih bersifat blocking dalam mengikuti pelatihan Cognitive Behavior Therapy sehingga data yang diperoleh dari subjek tersebut menjadi tidak valid. Sehingga dari 15 orang subyek, hanya 7 orang subyek yang data nya dapat dianalisis.

Subyek penelitian kelompok kontrol, semula berjumlah 15 orang. Namun pada sesi pertama dan kedua Beauty Class, subyek penelitian yang hadir berjumlah 10 orang pada sesi pertama dan kedua. Sehingga dari 15 orang subyek, hanya 10 orang subyek yang datanya dapat dianalisis karena 10 orang tersebut yang mengisi lembar prates dan pascates

Pengukuran body shame dilakukan dengan menggunakan Internalized Shame Scale dari Cook (1988) dan Objectified Body Consciousness Scales dari McKinley \& Hyde (1996) terdiri dari 59 aitem. Aspek perasaan malu menurut Gilbert dan Miles (2002) yaitu komponen kognitif sosial atau eksternal, komponen mengenai evaluasi diri yang berasal dari dalam, komponen emosi, komponen perilaku, dan komponen psikologis. Skala pengukuran yang digunakan untuk Body Shame adalah diferensial semantik.

Subyek diminta untuk memberikan respon terhadap dua kutub yang saling berlawanan arah dengan range angka 1-5. Semakin mendekati angka satu, pernyataan tersebut tidak sesusai dengan diri subyek. Sedangkan semakin mendekati angka 5, maka pernyataan tersebut sesuai dengan diri subyek.

Setelah diuji coba kepada subyek, tersisa 40 aitem dengan realibilitas sebesar 0.938. yang dibagi dua untuk prates dan pascates. Diketahui Cronbach's Alpha skala prates sebesar 0.872 dan Cronbach's Alpha skala pascates sebesar 0.888 .

Teknik analisis data yang digunakan untuk menguji hipotesis penelitian adalah One-Way ANOVA dengan menggunakan SPSS 22 for windows. Analisis ini digunakan untuk menentukan rata-rata dari dua kelompok ataupun lebih yang merupakan kelompok yang berbeda secara nyata (Trihendradi, 2012). 


\section{Prosedur intervensi}

Perlakuan yang diberikan pada kelompok eksperimen berupa Cognitive Behavior Therapy (CBT) yang terdiri dari lima sesi. Setiap sesi berdurasi satu jam. Subyek diberikan penugasan untuk melakukan evaluasi terhadap pemikiran yang dimilikinya pada sesi pertama dan sesi ketiga serta pada sesi kelima subyek diberikan penugasan untuk pencegahan relapse.

Sesi pertama mengenai asesmen dan diagnosa awal. Penugasan sesi pertama berupa Peta Masalah dan Catatan Pikiran. Peta Masalah berfungsi untuk menganalisis kaitan antara peristiwa, kognitif, afeksi, dan perilaku. Catatan Pikiran bertujuan untuk mengevaluasi pengaruh pikiran terhadap perasaan selain itu subyek diminta untuk memberikan nilai kekuatan terhadap kepercayaan yang dimiliki.

Pada sesi kedua yaitu mencari emosi negatif, pikiran otomatis, dan keyakinan utama. Sesi kedua diberikan feedback mengenai pengerjaan Catatan Pikiran dan Peta Masalah pada sesi pertama. Subyek diminta untuk menganalisis pemikiran negatifnya dengan bantuan eksperimen pikiran.

Sesi ketiga mengenai menyusun intervensi dengan memberikan konsekuensi positif dan negatif. Subyek diminta mengerjakan Lembar SMART untuk merumuskan sasaran perilaku yang akan dirubah. Setelah itu juga subyek diminta melakukan eksperimen perilaku lalu mencatatnya pada Catatan Pikiran II agar subyek mampu mengevaluasi perubahan yang terjadi dari perilaku yang sudah dilakukan. Catatan Pikiran II diberikan pada subyek sebagai tugas rumah dan subyek diminta untuk mengumpulkan lembar Catatan Pikiran II pada sesi kelima.

Sesi keempat berisi mengenai formulasi status, fokus terapi, intervensi tingkah laku. Pada sesi ini subyek diajarkan melakukan Self-Talk agar subyek melakukan perubahan perilaku adaptif yang dipengaruhi oleh pemikiran yang positif. Subyek diberikan kesempatan untuk praktik dan dipandu oleh terapis dalam melakukan Self-Talk.

Sesi terakhir berfokus pada pencegahan kekambuhan serta pascates. Subyek diminta mengerjakan Lembar Selfhelp dengan tujuan untuk mengevaluasi perubahan yang diperoleh selama kegiatan berlangsung dan membangkitkan potensi yang dimilikinya untuk mencegah timbulnya pikiran negatif dalam menghadapi masalah. Sebelum itu subyek juga diminta untuk mengumpulkan Lembar Catatan Pikiran II, lalu terapis memberikan feedback atas pengerjaan yang dimiliki subyek.

Beauty Class untuk kelompok kontrol terdiri dari dua sesi. Sesi yang pertama yaitu perkenalan dan edukasi skincare yang berdurasi 90 menit. Sesi kedua berisi mengenai edukasi alat dan produk make up dan pascates berdurasi 90 menit.

Perbedaan signifikan antara pemberian perlakuan berupa Cognitive Behavior Therapy (CBT) dan Beauty Class adalah pada tujuannya. Tujuan dari Cognitive Behavior Therapy (CBT) berusaha untuk mengubah pemikiran negatif pada individu yang mengalami body shame. Sedangkan pada Beauty Class memberikan edukasi mengenai cara merawat dan mempercantik diri secara fisik.

\section{HASIL}

Uji One-way ANOVA digunakan untuk mengetahui efektivitas Cognitive Behavior Therapy untuk menurunkan body shame. Selain itu, dengan menggunakan uji One-way ANOVA dapat dilihat adanya perubahan atau tidaknya body shame pada kelompok eksperimen dan kontrol. Berikut hasil analisis One-way ANOVA: 
TABEL 3.1 HASIL UJI HIPOTESIS

\begin{tabular}{lccccc}
\hline & JK & Db & Mean Square & F & Sig. \\
\hline Between Groups & 2167.397 & 3 & 722.466 & 4.487 & .010 \\
Within Groups & 4830.486 & 30 & 161.016 & & \\
\hline Total & 6997.882 & 33 & & & \\
\hline
\end{tabular}

Mengetahui efektivitas Cognitive Behavior Therapy untuk menurunkan body shame dapat dilihat pada kolom sig. Pada hasil uji hipotesis diperoleh nilai $\mathrm{F} 4.487$ dengan signifikasi sebesar $0.010(\mathrm{p}<0.05)$, hal ini menunjukkan bahwa hipotesis alternatif diterima sedangkan hipotesis nol ditolak. Sehingga dapat diketahui bahwa Cognitive Behavior Therapy efektif untuk menurunkan body shame.

Tabel 3.2 Hasil Post Hoc

\begin{tabular}{lll}
\multicolumn{1}{c}{ Perlakuan } & \multicolumn{1}{c}{ Perbedaan Rerata } & \multicolumn{1}{c}{$\boldsymbol{p .}$} \\
\hline Pre * Post Kelompok Kontrol & 0.000 & 1.00 \\
Pre * Post Kelompok Eksperimen & 14.85714 & 0.036 \\
\hline
\end{tabular}

Perbedaan antara kelompok kontrol yang mendapatkan perlakuan berupa Beauty Class dan kelompok eksperimen yang mendapatkan perlakuan Cognitive Behavior Therapy. Diketahui bahwa terdapat signifikasi pada kelompok eksperimen yang ditunjukkan pada nilai Post-Hoc dengan signifikasi sebesar 0.036. Hal tersebut menunjukkan bahwa adanya pengaruh yang signifikan antara Cognitive Behavior Therapy dengan body shame. Sedangkan pada kelompok kontrol tidak terdapat perubahan body shame yang ditunjukkan dari nilai signifikasi pada Post-Hoc sebesar 1.000 . Pemberian perlakuan berupa Beauty Class pada kelompok kontrol tidak memberikan pengaruh yang signifikan terhadap subyek.

Diketahui perbedaan antara kelompok kontrol yang mendapatkan perlakuan berupa Beauty Class dan kelompok eksperimen yang mendapatkan perlakuan
Cognitive Behavior Therapy. Diketahui bahwa terdapat penurunan mean pada kelompok eksperimen yang ditunjukkan pada nilai rerata prates sebesar 58.7143 dan nilai rerata pascates sebesar 43.8571 . Pemberian perlakuan Cognitive Behavior Therapy pada kelompok eksperimen memberikan pengaruh terhadap subyek berupa penurunan. Sedangkan pada kelompok kontrol tidak terdapat perubahan body shame yang ditunjukkan nilai rerata prates sebesar 64.3000 dan nilai rerata pascates sebesar 64.3000. Pemberian perlakuan berupa Beauty Class pada kelompok kontrol tidak memberikan pengaruh yang signifikan terhadap subyek. Perubahan yang terjadi selama pemberian perlakuan antara kelompok kontrol dan kelompok eksperimen disajikan pada grafik berikut: 
Gambar 3.1 Estimated Marginal Means of Body Shame

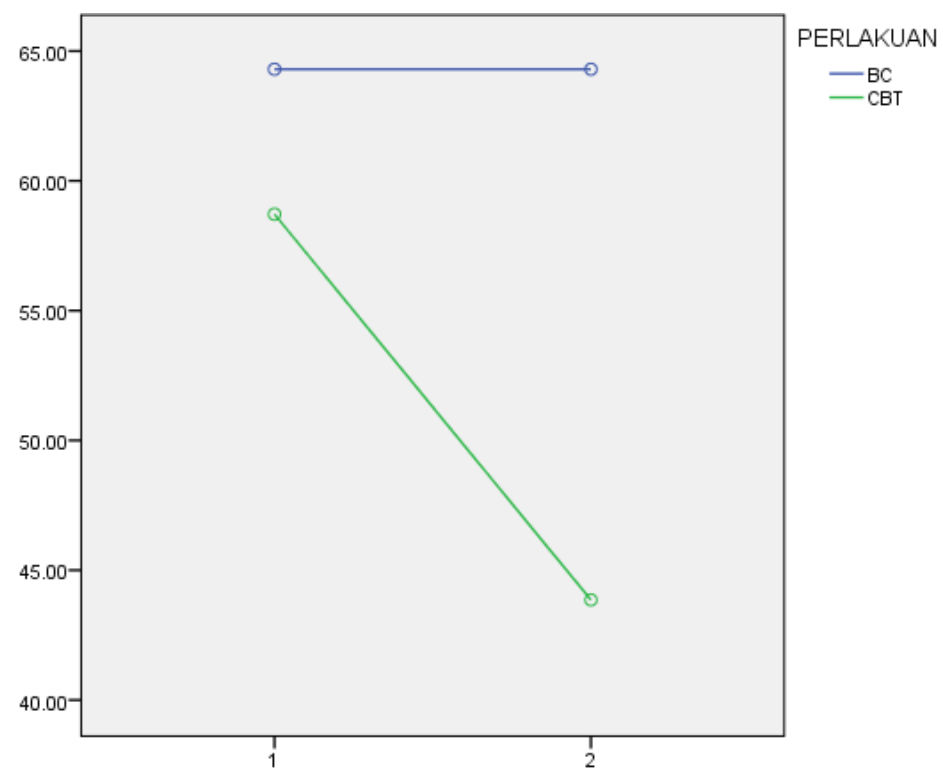

Cognitive Behavior Therapy lebih efektif untuk menurunkan body shame dibandingkan Beauty Class. Sehingga Cognitive Behavior Therapy mampu digunakan sebagai penanganan body shame. Sedangkan Beauty Class kurang efektif untuk digunakan sebagai penanganan body shame. Sehingga hipotesis pada penelitian ini diterima yakni Cognitive Behavior Therapy (CBT) efektif untuk menurunkan tingkat body shame.

\section{PEMBAHASAN}

Berdasarkan hasil uji analisis One-way ANOVA diketahui asumsi nilai signifikasi dengan $0.010<0.05$ sehingga diketahui bahwa Cognitive Behavior Therapy berpengaruh terhadap penurunan body shame. Pemaparan mengenai manfaat dari Cognitive Behavior Therapy berdasarkan manipulation check diketahui bahwa subyek merasa adanya perbedaan setelah dan sebelum mendapatkan perlakuan Cognitive Behavior Therapy.

Perbandingan antara pemaparan subyek sebelum dan sesudah pemberian perlakuan, memperlihatkan bahwa adanya perubahan pada diri subyek. Subyek lebih mampu menerima dirinya serta menghilangkan perasaaan khawatir dan cemas. Hal tersebut membuat subyek lebih percaya diri dan menjadi diri sendiri karena tidak memperdulikan perkataan negatif dari orang lain

Hasil prates dan pascates subyek juga memperlihatkan adanya penurunan skor serta tingkat body shame subyek. Semua subyek brada pada kategori dibawah rata dan enam dari tujuh orang mengalami penurunan skor. Sehingga dapat dikatakan bahwa Cognitive Behavior Therapy memiliki pengaruh yang signifikan untuk menurunkan tingkat body shame individu. Sedangkan pada kelompok kontrol, tingkat body shame subyek berada pada kategori yang acak dan skor yang dimiliki subyek juga tidak semua subyek mengalami penurunan.

Berdasarkan hasil penelitian bahwa Beauty Class yang diberikan pada kelompok kontrol kurang efektif untuk menurunkan body shame. Walaupun iklan kosmetik maupun skincare menjamin mampu 
menutupi kekurangan fisik yang ada sehingga lebih tampil percaya diri dan memberikan pemaparan bahwa orang yang cantik sekalipun tidak akan terhindar dari pengawasan orang lain (Northrop, 2012). Sehingga klaim yang ditawarkan oleh produk kosmetik tidak sesuai dengan hasil penelitian ini karena body shame subyek yang mengikuti Beauty Class tidak mengalami penurunan.

Keberhasilan Cognitive Behavior Therapy menurunkan body shame dengan menghilangkan evaluasi negatif individu terhadap tubuhnya. Evaluasi negatif disebabkan oleh membandingkan orang lain dengan dirinya dan kritikan dari orang yang membuat subyek menginternalisasikan hal tersebut dalam dirinya. Individu membutuhkan cara untuk mengatasi hal tersebut agar tidak merasakan malu terhadap tubuhnya. Menolak pandangan mengenai standar kecantikan yang terdapat pada masyarakat merupakan hal yang penting untuk menumbuhkan rasa percaya diri mengenai penampilan yang dimiliki. Kepercayaan mengenai tidak adanya pandangan yang obyektif mengenai kecantikan membuat individu sadar bahwa perkataan maupun pandangan disebut terlalu jelek maupun terlalu cantik tidak berdasarkan dari penampilan fisiknya namun timbul dari standar yang ada (Wolf, 2004).

\section{Cognitive Behavior Therapy efektif} untuk mengatasi gangguan makan. Melakukan perubahan kognisi yang semula terdapat distorsi kognitif yaitu semua atau tidak sama sekali juga membantu untuk mengatasi gangguan makan dan melakukan pelatihan asertif untuk menghadapi tuntutan dari orang lain (Davidson, Neale, \& Kring, 2014). Kemampuan individu dalam melakukan rekonstruksi pikiran sangatlah penting karena mampu mengubah mindset yang tertanam dalam diri individu mengenai standar kecantikan yang ada bahwa kecantikan seseorang tidak dinilai berdasarkan standar yang ada.

Pemaparan subyek sebelum dan sesudah diberikan perlakuan Cognitive Behavior Therapy menunjukkan pandangan positif terhadap dirinya. Subyek menjadi lebih percaya diri dengan penampilannya dan menerima kondisi fisik dirinya. Cognitive Behavior Therapy efektif dalam meningkatkan citra diri individu sehingga mampu mengurangi pandangan negative terhadap fisik individu (Fitri, Badrudjaman, \& Fazriah, 2017). Setelah diberikan Cognitive Behavior Therapy individu cenderung menghargai dirinya dan tidak merasa minder dengan orang lain untuk menampilkan kondisi fisiknya.

Distorsi kognitif subyek mengenai penampilannya dapat diatasi dengan Cognitive Behavior Therapy karena membantu subyek untuk mengevaluasi pemikirannya. Sejalan dengan hasil penelitian dari Butters dan Cash (1987) bahwa Cognitive Behavior Therapy mampu untuk menurunkan tingkat kesalahan kognitif pada individu yang mengidap body dissatisfaction. Hal tersebut ditunjukkan ketika subyek tidak memperdulikan lagi aturan mengenai berat badan ideal dan menilai bahwa penampilan subyek menarik.

Belajar ketrampilan untuk mengatasi masalah sangatlah penting untuk mengatasi perasaaan cemas saat menghadapi peristiwa yang tidak menyenangkan (Jones, 2011). Perlakuan Cognitive Behavior Therapy merupakan salah satu bentuk edukasi untuk menghadapi peristiwa yang kurang menyenangkan. Body shaming merupakan tindakan yang kurang menyenangkan sehingga membutuhkan strategi untuk mengatasi hal tersebut. Sehingga berdasarkan penelitian ini, Cognitive Behavior Therapy mampu untuk menghadapi body shame dan membangun pertahanan diri individu dari dalam.

$$
\text { Cognitive Behavior Therapy }
$$

bermanfaat bagi diri individu untuk 
mengendalikan pemikiran yang negatif. Pada kelompok eksperimen, subyek dilatih untuk mengevaluasi masalah yang dialami dengan bukti dari pemikiran subyek untuk mengetahui kecocokan antara pemikiran dan kondisi nyata yang subyek alami. Selain itu, subyek juga berlatih untuk melakukan perubahan perilaku dengan melakukan selftalk agar subyek mampu untuk menanamkan perasaan percaya diri terhadap tubuhnya dan berpikir positif mengenai keadaan fisiknya saat ini.

Mengatasi body shame dapat dilakukan secara individual tanpa bantuan dari terapis. Mencoba untuk melatih pemikiran dengan mengevaluasi pemikiran yang ada membuat individu tidak mudah untuk menyimpulkan atau menjustifikasi sesuatu. Metode yang dapat digunakan dengan bantuan catatan pikiran agar lebih mudah untuk mengevaluasi setiap peristiwa dan menemukan bukti dari pemikiran yang ada.

Melalui pendekatan Cognitive Behavior Therapy, selain melakukan evaluasi individu juga diajak untuk mengubah perilakunya agar mampu mengetahui manifestasi dari perubahan pikiran yang ada. Mengatasi body shame dengan menggunakan Cognitive Behavior Therapy membutuhkan adanya keinginan untuk berubah agar dapat mencapai perubahan yang dikehendaki selain itu dibutuhkan adanya kemampuan berpikir secara logis, terbuka terhadap keadaan yang dialami, serta sikap pantang menyerah dalam melakukan Cognitive Behavior Therapy.

Cognitive Behavior Therapy (CBT) memiliki karakteristik yaitu tidak dapat diterapkan pada individu yang ingin mengeksplorasi masa lalunya dan hanya dapat diterapkan pada individu yang cerdas serta mampu menyampaikan pemikirannya
(Wilding \& Milne, 2013). Sehingga subyek penelitian ini merupakan mahasiswi yang memiliki kemampuan untuk berpikir logis dan bersedia mengungkapkan perasaannya. Selain itu Cognitive Behavior Therapy memandang bahwa masa lalu individu tidak dapat memberikan perubahan yang signifikan karena Cognitive Behavior Therapy mengarahkan individu terhadap kepercayaan yang mampu mengubah masa sekarang dan masa depan individu daripada menganalisis kepercayaan masa lalu yang tidak sesuai dengan masa sekarang.

Implementasi dari hasil penelitian ini pada masyarakat adalah pentingnya menanamkan pemikiran untuk mencintai diri sendiri dan menghargai diri agar mampu menjadi individu yang lebih positif. Selain itu diharapkan adanya edukasi mengenai citra kecantikan yang berbeda pada setiap diri individu agar tidak mudah melakukan justifikasi maupun memberikan komentar atau hujatan terhadap penampilan orang lain. Sehingga mampu menciptakan toleransi terhadap perbedaan yang ada.

Namun terdapat keterbatasan pada penelitian ini yaitu kurangnya jumlah subyek penelitian sehingga kurang memberikan gambaran yang luas mengenai efektivitas Cognitive Behavior Therapy untuk menurunkan body shame. Selain itu tidak adanya randomisasi untuk penempatan subyek dalam kelompok kontrol dan kelompok eksperimen sehingga kurangnya pengontrolan terhadap variabel noneksperimental karena subyek tidak terbagi secara seimbang. Alasan peneliti tidak melakukan randomisasi disebabkan subyek penelitian dipengaruhi oleh motivasi mengikuti perlakuan karena adanya perbedaan jumlah sesi pada Beauty Class dan Cognitive Behavior Therapy. 


\section{DAFTAR PUSTAKA}

Butters, J., \& Cash, T. (1987). CognitiveBehavioral Treatment of Women's Body Image Disscatifaction. Journal of Consulting and Clinical Psychology, 55 (6), 889-897.

Davidson, G., Neale, J., \& Kring, A. (2014). Psikologi Abnormal Edisi Ke 9. Jakarta: PT Raja Grafindo Persada.

Daye, C., Webb, J., \& Jafari, N. (2014). Exploring Self-Compassion as a Refuge Against Recalling The BodyRelated Shaming of Caregiver Eating Messages on Dimensions of Objectified Body Consciousness in College Women. Body Image 11, $547-$ 556.

Dinartika, N., Wisnuwardhani, D., \& Arbiyah, N. (2014). Prediksi Relationship Contigency Dan Self-Efficacy Dalam Hubungan Romantis Terhadap Body Shame Pada Dewasa Muda. Psibernetika, 7 (2), 132-152.

Fitri, S., Badrudjaman, A., \& Fazriah, R. (2017). Pengaruh Konseling Kelompok dengan Pendekatan Body Image-Cognitive Behavior Therapy (BI-CBT) terhadap Siswa SMK yang Memiliki Citra Tubuh Negatif. Insight,6(2), 206-222.

Gilbert, P., \& Miles, J. (2002). Body Shame Conceptualisation, Research, and Treatment. New York: BrunnerRoutledge.
Jones, R. (2011). Teori dab Praktik Konseling dan Terapi Edisi Keempat. Yogyakarta: Pustaka Pelajar.

Myers, D. (2012). Psikologi Sosial Edisi Ke 10 Jilid 1. Jakarta: Salemba Humanika.

Northrop, J. (2012). Reflecting on Cosmetic Surgery Body image, Shame and Narcissism. New York: Routledge.

Palmer, S. (2011). Konseling dan Psikoterapi. Yogyakarta: Pustaka Pelajar.

Putranto, A. (2016). Aplikasi Cognitive Behavior dan Behavior Activation dalam Intervensi Klinis. Jakarta: Grafindo Books Media.

Putri, P. (2018). Kajian Sosiologis Penyimpangan Tindakan Suntik Pemutih Kulit. Jurnal Cepalo, 1 (2), 80-89.

Trihendradi, C. (2012). Step by Step SPSS 20 Analisis Data Statistik. Yogyakarta: CV Andi Offset.

Wilding, C., \& Milne, A. (2013). Cognitive Behavioural Therapy. Jakarta: Indeks.

Wolf, N. (2004). Mitos Kecantikan Kala Kecantikan Menindas Perempuan. Yogyakarta: Niagara. 